1 Molecular Microbiology Group, University of Southampton Medical School, Southampton General Hospital, Southampton SO16 6YD UK

2 Department of Microbiology, National University of Singapore, Singapore

3 Department of Medical Microbiology, Imperial College School of Medicine at St Mary's, Paddington, London W2 1PG, UK

\section{Variation within serovars of Neisseria gonorrhoeae detected by structural analysis of outer-membrane protein PIB and by pulsed- field gel electrophoresis}

\author{
Susan J. Cooke, ${ }^{1} \dagger$ Helen de la Paz, Chit La Poh, ${ }^{2}$ Catherine A. Ison ${ }^{3}$ and \\ John E. Heckels ${ }^{1}$
}

Author for correspondence: John E. Heckels. Tel: +44 1703 796974. Fax: +44 1703774316. e-mail: jeh@southampton.ac.uk

\begin{abstract}
Outer-membrane protein PI is the antigen responsible for serovar specificity of Neisseria gonorrhoeae and is a potential vaccine target. In order to investigate possible hidden variation within a serovar, the sequence of the por genes encoding protein PIB have been obtained from a series of strains, including isolates known to be epidemiologically linked. The inferred amino acid sequences of the PIB molecules of isolates from known sexual contacts were identical, but non-related isolates showed significant heterogeneity in PIB sequence. These differences were not confined to the two variable regions (Var1 and Var2) which have previously been identified, but were largely, although not exclusively, located in regions predicted to form one of eight surface-exposed loops. The isolates were subjected to pulsed-field gel electrophoresis of restriction digests of chromosomal DNA, which also demonstrated identity between linked strains but revealed diversity within a serovar. The deduced amino acid sequences of PIB were also used to synthesize peptides for epitope-mapping experiments. These revealed that some mAbs, used to define serovar specificity, recognized linear epitopes located in loops 5 and 6, while others appeared to recognize conformational epitopes elsewhere in the molecule. The occurrence of the sequence differences within a serovar, which are not detected by the serotyping reagents, reveals that PIB represents a potential source of information which should permit considerably more detailed epidemiological studies than are currently possible and focuses attention on more conserved regions of the protein as potential targets for vaccination.
\end{abstract}

Keywords: gonococcal PIB, outer-membrane protein $\mathrm{PIB}$, Neisseria gonorrhoeae serovars

\section{INTRODUCTION}

The major protein present on the surface of Neisseria gonorrboeae is protein I (PI), an anion-selective porin (Douglas et al., 1981). Unlike the other major surface antigens, pili, Opa (PII) and LPS, PI does not undergo

†Present address: Clinical Biochemistry, University of Southampton Medical School.

The GenBank accession numbers for the sequences reported in this paper are U74631-U74643. antigenic shift during infection (Zak et al., 1984). Antibodies directed against PI activate complementmediated killing, promote phagocytosis by polymorphonuclear leukocytes and inhibit interaction with epithelial cells (Virji et al., 1986, 1987). Although PI is stable within a strain, structural variations occur which generate antigenic differences between strains (Butt et al., 1990b). Thus, in addition to its essential physiological role, PI is of particular significance both as the antigen responsible for serological classification of strains and as a potential vaccine candidate.

Biochemical studies have differentiated PI into two 
major classes, PIA and PIB, which differ in molecular mass and susceptibility to proteolysis (Sandstrom et al., 1982). Each class can be further subdivided into a number of serovars based on patterns of reaction with panels of either PIA- or PIB-specific mAbs (Knapp et al., 1984). This classification into serovars provides an important base for the differentiation between strains in epidemiological studies (Knapp et al., 1987; Ison et al., 1992).

Information on the structural basis of gonococcal serological specificity has been obtained following the sequencing of the por genes, which encode PIA and PIB. Despite the biochemical and antigenic differences between PIA and PIB, considerable similarity exists between the inferred amino acid sequences of the two classes, with about $70 \%$ of amino acid residues in common (Carbonetti \& Sparling, 1987; Gotschlich et al., 1987). Even greater homology is seen within each class. Comparison of the amino acid sequences of PIB from three different gonococcal strains revealed over $95 \%$ homology between the strains, with most differences being clustered in two regions around residues 196 and 237. Sequencing these regions from four further strains of a different serovar confirmed the variability of these two regions, which were designated variable regions 1 and 2 (Var1 and Var2) (Butt et al., $1990 \mathrm{~b}$ ). The importance of these regions for antigenic specificity was confirmed using overlapping synthetic peptides, corresponding to the entire PIB sequence, to map the location of epitopes recognized by PIB-specific $\mathrm{mAbs}$. In each case the epitopes were localized to the Var1 region (Butt et al., 1990b).

Recent studies have revealed that further variations may occur within the Neisseria porins which are not revealed by current serological methods. Comparison of the PIA sequences from two unrelated strains of identical serovar revealed a 'silent' amino acid difference between the strains (Mee et al., 1993). Further sequence differences have been demonstrated within sero-subtypes of the related meningococcal class 1 porin, and these permitted much more detailed differentiation between epidemiologically related strains (Brooks et al., 1995). The current method of differentiating gonococcal isolates relies on agglutination reactions with $\mathrm{mAbs}$ to define the serovar. This approach has proved very useful for monitoring temporal changes in gonococcal populations, but gives limited information for forensic purposes or for studying sexual networks. In many geographical locations a limited number of serovars account for the majority of the gonococci. Hence, in such a population, isolates known to be from a single source or sexual contact will belong to identical serovars (Ison et al., 1992), but isolates from a different source may also be of that same serovar. We have therefore investigated the use of molecular methods based on PIB sequence analysis and restriction endonuclease digestion of gonococcal DNA to differentiate between gonococcal strains which show similar reactivity in serovar determination, including some strains known to be epidemiologically linked.

\section{METHODS}

Source of bacterial strains and growth conditions. Isolates of Neisseria gonorrboeae from known sexual contacts attending the Department of Genitourinary Medicine at Basingstoke District Hospital were obtained from the cervix and urethra of females (denoted $C$ and $U$ respectively) and from the urethra of their male partners in a previous study (Zak et al., 1984). Additional isolates, not known to be from linked cases, were from patients attending the same clinic (designated SU strains). Strains of defined serovar were from the culture collection at St Mary's Hospital Medical School (IB-2 strains 3039, 3020, 3615 and 3582 ; IB-3 strains 3682 and 3668 ). All bacteria were grown on proteose peptone agar at $37^{\circ} \mathrm{C}$ in $5 \%(\mathrm{v} / \mathrm{v}) \mathrm{CO}_{2}$ (Mee et al., 1993).

Serotyping and monoclonal antibody reactivity. Serotyping was performed by co-agglutination reaction with the panel of $12 \mathrm{mAbs}$ (Genetic Systems) directed against epitopes on PI, using the nomenclature of Knapp et al. (1984) as described by Gill (1991).

Dot-blot analysis was carried out as described previously (Mee et al., 1993) using the same panel of antibodies and a second panel of mAbs (SM mAbs) directed against gonococcal PIB which have been previously characterized (Virji et al., 1986; Butt et al., 1990b).

Sequence analysis of PIB. The sequences of the por genes encoding PIB were determined following selective amplification of the gene by PCR. A few gonococcal colonies were resuspended in water $(200 \mu \mathrm{l})$ and were lysed by the addition of $0.25 \mathrm{M} \mathrm{KOH}(400 \mu \mathrm{l})$ and heating to $100^{\circ} \mathrm{C}$ for $5 \mathrm{~min}$. The lysate was neutralized by the addition of $0.5 \mathrm{M} \mathrm{Tris} / \mathrm{HCl}$ $\mathrm{pH} 7 \cdot 5(400 \mu \mathrm{l})$ and diluted 1:100 for use in PCR. The oligonucleotides used corresponded to the previously determined $5^{\prime}$ terminus (5'-CCAAAAAAGGAATACAGC- $\left.3^{\prime}\right)$ and $3^{\prime}$ terminus $\left(5^{\prime}\right.$-GCAGATTAGAATTTGTGG-3') of the por gene of gonococcal strain P9 (Butt et al., 1990a). The reaction mixture $(100 \mu \mathrm{l})$ contained the diluted bacterial lysate in the presence of $50 \mathrm{mM} \mathrm{KCl}, 10 \mathrm{mM}$ Tris $/ \mathrm{HCl} \mathrm{pH} \mathrm{9.0,}$ $0.1 \%$ Triton X-100, $1.5 \mathrm{mM} \mathrm{MgCl}_{2}, 0.2 \mathrm{mM}$ of each dNTP (BCL), 400 ng of each primer and $5 \mathrm{U}$ Taq DNA polymerase (Promega). Amplification was performed in a GeneAmp 9600 (Perkin-Elmer Cetus) using 30 cycles of denaturation at $94^{\circ} \mathrm{C}$ for $15 \mathrm{~s}$, primer annealing at $48^{\circ} \mathrm{C}$ for $20 \mathrm{~s}$ and DNA polymerization at $72{ }^{\circ} \mathrm{C}$ for $30 \mathrm{~s}$. The final cycle was followed by an additional polymerization step at $72{ }^{\circ} \mathrm{C}$ for $3 \mathrm{~min}$. Excess PCR primers were removed and the amplified DNA concentrated twofold using the Magic PCR preps DNA purification system (Promega).

The purified DNA was used in sequencing reactions with a Taq DyeDeoxy Terminator cycle sequencing kit (ABI) according to the manufacturer's instructions, with $200 \mathrm{ng}$ DNA and $15 \mathrm{ng}$ sequencing primer in a final reaction volume of $24.5 \mu \mathrm{l}$ was used. The cycle sequencing reactions were carried out using 25 cycles of denaturation at $96^{\circ} \mathrm{C}$ for $15 \mathrm{~s}$, primer annealing at $52^{\circ} \mathrm{C}$ for $10 \mathrm{~s}$ and DNA polymerization at $60^{\circ} \mathrm{C}$ for $4 \mathrm{~min}$. After removal of unincorporated nucleotides, the resulting products were analysed using a model 373 automated DNA sequenator (ABI). Sequencing of both strands of the por gene was accomplished with additional oligonucleotide primers based on the sequence of the por gene from strain P9 (Butt et al., 1990a).

Pulsed-field gel electrophoresis (PFGE). Gonococcal chromosomal DNA was prepared and digested with the restriction endonuclease SpeI, as described by Poh \& Lau (1993). Briefly, gonococcal cultures were harvested, washed, resuspended in 
Table 1. Comparison of gonococcal isolates determined to belong to serovar IB-2 on initial isolation

Isolates were reacted with mAbs under standard co-agglutination conditions for determination of serovar (Gill, 1991) and also reacted with the same mAbs in dot-blots (Mee et al., 1993). Auxotype was determined as described by Ison et al. (1992). NR, No requirement.

\begin{tabular}{|c|c|c|c|c|c|c|c|c|c|c|}
\hline \multirow[t]{2}{*}{ Strain } & & \multirow[t]{2}{*}{ Auxotype } & \multirow[t]{2}{*}{ Test } & \multicolumn{6}{|c|}{ Serotyping PIB mAbs: } & \multirow{2}{*}{$\begin{array}{c}\text { Apparent } \\
\text { serovar }\end{array}$} \\
\hline & & & & $3 \mathrm{C} 8$ & 1F5 & 2D6 & $2 \mathrm{G} 2$ & 2D4 & $2 \mathrm{H} 1$ & \\
\hline $\begin{array}{l}\text { SU80 } \\
\text { SU81C } \\
\text { SU81U } \\
\text { SU82C }\end{array}$ & (Cohort 1) & AHU & $\begin{array}{l}\text { Co-Agg } \\
\text { D-Blot }\end{array}$ & $\begin{array}{l}+ \\
+\end{array}$ & $\begin{array}{l}+ \\
-\end{array}$ & $\begin{array}{l}- \\
-\end{array}$ & $\begin{array}{l}- \\
-\end{array}$ & - & $\begin{array}{l}+ \\
+\end{array}$ & $\begin{array}{l}\text { IB-3 } \\
\text { IB-6 }\end{array}$ \\
\hline SU105 & & $\mathrm{AHU}$ & $\begin{array}{l}\text { Co-Agg } \\
\text { D-Blot }\end{array}$ & $\begin{array}{l}+ \\
+\end{array}$ & $\begin{array}{l}+ \\
-\end{array}$ & $\begin{array}{l}- \\
-\end{array}$ & - & $\begin{array}{l}- \\
-\end{array}$ & $\begin{array}{l}+ \\
+\end{array}$ & $\begin{array}{l}\text { IB-3 } \\
\text { IB-6 }\end{array}$ \\
\hline $\begin{array}{l}\text { SU50 } \\
\text { SU51U } \\
\text { SU51C }\end{array}$ & (Cohort 2) & $\mathrm{PA}$ & $\begin{array}{l}\text { Co-Agg } \\
\text { D-Blot }\end{array}$ & $\begin{array}{l}+ \\
+\end{array}$ & $\begin{array}{l}- \\
-\end{array}$ & $\begin{array}{l}+ \\
+\end{array}$ & - & - & $\begin{array}{l}+ \\
+\end{array}$ & $\begin{array}{l}\text { IB-2 } \\
\text { IB-2 }\end{array}$ \\
\hline SU104 & & NR & $\begin{array}{l}\text { Co-Agg } \\
\text { D-Blot }\end{array}$ & $\begin{array}{l}+ \\
+\end{array}$ & $\begin{array}{l}- \\
-\end{array}$ & $\begin{array}{l}+ \\
+\end{array}$ & $\begin{array}{l}- \\
-\end{array}$ & $\begin{array}{l}- \\
-\end{array}$ & $\begin{array}{l}+ \\
+\end{array}$ & $\begin{array}{l}\text { IB-2 } \\
\text { IB-2 }\end{array}$ \\
\hline SU103 & & NR & $\begin{array}{l}\text { Co-Agg } \\
\text { D-Blot }\end{array}$ & $\begin{array}{l}+ \\
+\end{array}$ & $\begin{array}{l}- \\
-\end{array}$ & $\begin{array}{l}+ \\
+\end{array}$ & $\begin{array}{l}- \\
-\end{array}$ & $\begin{array}{l}- \\
-\end{array}$ & $\begin{array}{l}+ \\
+\end{array}$ & $\begin{array}{l}\text { IB-2 } \\
\text { IB-2 }\end{array}$ \\
\hline SU92 & & NR & $\begin{array}{l}\text { Co-Agg } \\
\text { D-Blot }\end{array}$ & $\begin{array}{l}+ \\
+\end{array}$ & $\begin{array}{l}- \\
-\end{array}$ & $\begin{array}{l}+ \\
+\end{array}$ & $\begin{array}{l}- \\
-\end{array}$ & $\begin{array}{l}- \\
-\end{array}$ & $\begin{array}{l}+ \\
+\end{array}$ & $\begin{array}{l}\text { IB-2 } \\
\text { IB-2 }\end{array}$ \\
\hline
\end{tabular}

$1 \mathrm{M} \mathrm{NaCl}$ in $10 \mathrm{mM}$ Tris/ $\mathrm{HCl}$ and mixed with an equal volume of $1 \%$ low-melting-point agarose at $42{ }^{\circ} \mathrm{C}$. After solidifying, the plugs were transferred to lysis solution containing $6 \mathrm{mM} \mathrm{HCl}, 100 \mathrm{mM}$ EDTA, $0.5 \%$ Brij 58, 0.2\% sodium deoxycholate, $0.5 \%$ sodium lauryl sarcosinate, $10 \mathrm{mg} \mathrm{m}^{-1}$ lysozyme and $1 \mathrm{U} \mathrm{ml}^{-1}$ RNase, and incubated at $37^{\circ} \mathrm{C}$ overnight. After further incubation in $0.5 \mathrm{M}$ EDTA (pH 9-9.5) containing 1\% sodium lauryl sarcosinate and $500 \mu \mathrm{g}$ proteinase $\mathrm{K} \mathrm{ml}^{-1}$, the prepared plugs were digested with $10 \mathrm{U}$ endonuclease in $150 \mu \mathrm{l}$ restriction buffer (New England Biolabs).

The digested plugs were sealed into slots of a $1 \%$ agarose gel (SeaKem GTG agarose, FMC) and subjected to electrophoresis in a contour-clamped homogeneous-electric-field apparatus with a hexagonal electrode array (Bio-Rad) for $20 \mathrm{~h}$ at $200 \mathrm{~V}$ (Poh \& Lau, 1993). Gels were stained with ethidium bromide and photographed under UV transillumination. After photography, the negatives were scanned using a flat-bed scanner (Epson) and the resulting images were analysed using GelManager software (BioSystematica).

Multiple solid-phase peptide synthesis and epitope mapping. Multiple solid-phase peptide synthesis was carried out with the aid of an Epiguide (Labsystems) using pin technology with a commercially available kit (CRB) as described in detail by Butt et al. (1990a) and McGuinness et al. (1993). Immunological reactivity of the peptides with mAbs was assayed by ELISA and the peptides were re-used after bound antibody was dissociated by sonication of the pins for $30 \mathrm{~min}$ in $1 \%$ SDS, $0 \cdot 1 \% 2$-mercaptoethanol in $0 \cdot 1 \mathrm{M}$ phosphate buffer at $60^{\circ} \mathrm{C}$. Immunological reactivity was always observed in duplicate peptides and in assays repeated on at least two occasions.

Sequence analysis. Sequence comparisons were carried out using DNAstar (Lasergene) and with the GCG sequence analysis programs using the BBSRC SEQNET facility.

\section{RESULTS \\ Definition of strains}

All strains originally isolated by Zak et al. (1984) which were serotyped as IB-2 at the time of isolation were chosen for detailed study. These included two groups of isolates known to be epidemiologically linked: cohort 1 (four isolates) and cohort 2 (three isolates). Subsequent serotyping showed that the isolates from cohort 1 and one additional strain were serovar IB-3 (Table 1).

In addition to serotyping, the isolates were also subjected to dot-blot analysis, using the same mAbs as used to determine the serovar by co-agglutination. Two distinct patterns of reactivity were observed (Table 1 ). The serovar IB-2 strains (including cohort 2) gave identical results with both methods, while the IB- 3 strains failed to react in dot-blots with mAb 2D6. Since the latter pattern, in co-agglutination, denotes serovar IB-6, the isolates which reacted in this manner in dot-blots were designated IB-3 (d.b.-6). Despite the unexpected differences in immunological reactivity seen between the strains, the isolates from within each cohort always reacted identically, cohort 2 reacting as IB-2 and cohort 1 as IB3 (d.b.-6).

The isolates were also reacted by dot-blotting with the SM panel of mAbs, which have previously been used in immunochemical analysis of PIB (Virji et al., 1986; Butt 

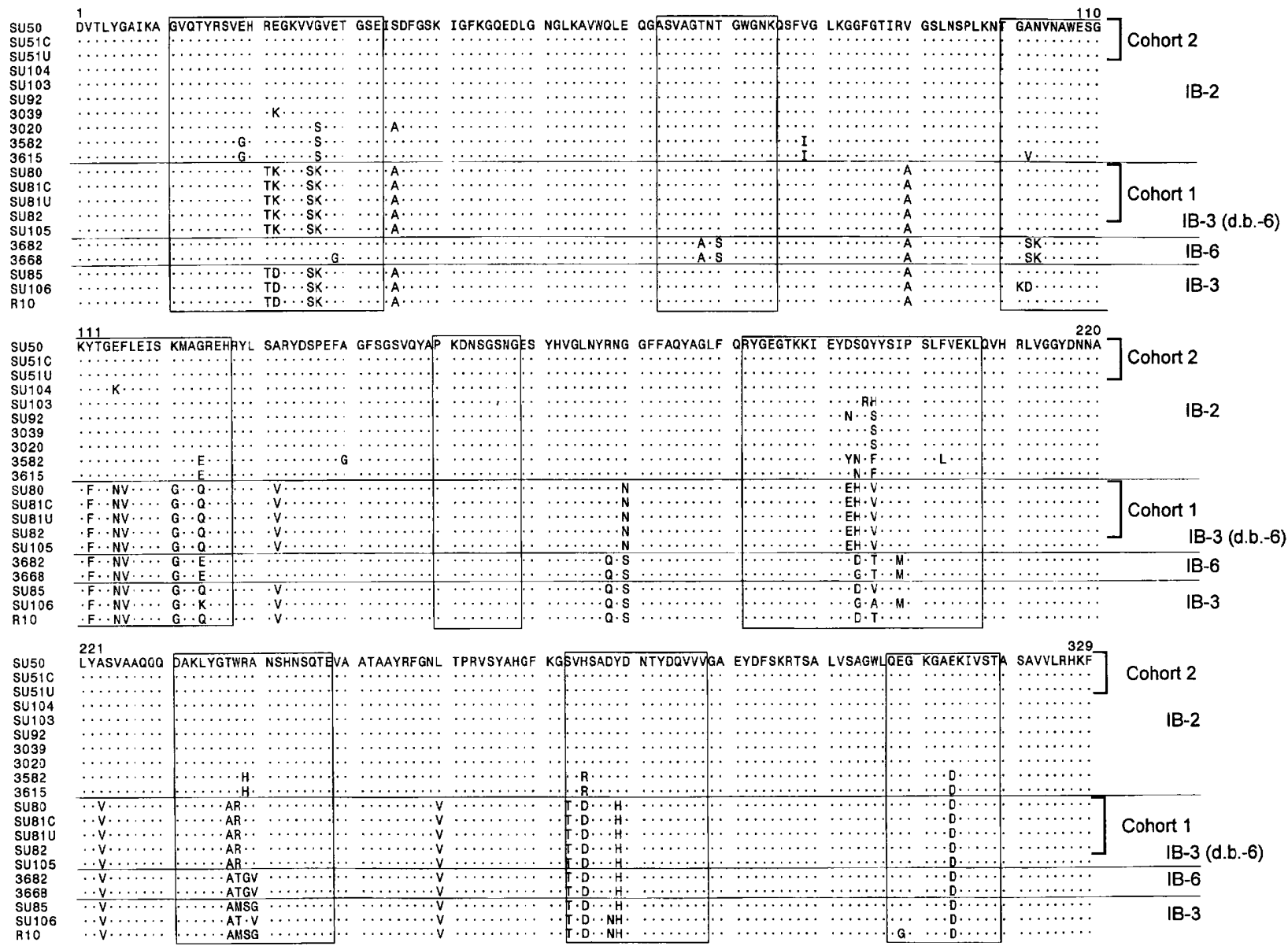

Fig. 1. Comparison of predicted amino acid sequences of PIB from gonococcal isolates. Dots indicate positions with identity to the sequence of strain SU50. Boxes indicate the regions predicted to form surface-exposed loops according to the model of Van der Ley et al. (1991). Horizontal lines separate strains according to serovar, and brackets enclose sequences from cohorts 1 and 2. The sequence of PIB from strain R10 is from Gotschlich et al. (1987).

et al., 1990b). Again, the two groups of strains could be distinguished: the first group reacted with all five $\mathrm{mAbs}$ tested, while the second group reacted with mAbs SM24 and SM198, but failed to react with mAbs SM21, SM23 and SM203.

\section{Comparison of PIB sequences}

In order to investigate the structural basis for serological specificity and the potential variation of PIB within a serovar, the por gene was sequenced from all the isolates described above, together with standard strains which reacted unequivocally in both co-agglutination and dotblots as either serovar IB-3 or IB-6. The corresponding translated protein sequences are shown in Fig. 1. Significant sequence differences were seen between the strains. A dendrogram of the relationships between the sequences revealed that they fell into four distinct groups which precisely corresponded to the four patterns of immunological reactivity demonstrated by the strains, namely IB-2, IB-3 (d.b.-6), IB-3 and IB-6 (Fig. 2).
The four isolates from cohort 1 , which belonged to serovar IB-3 (d.b.-6), came from one male and two female contacts and all gave an identical amino acid sequence. This sequence was also identical to that of the one other isolate (SU105) which was also IB-3 (d.b.-6). This isolate, which was not known to be clinically related to cohort 1 , was obtained 1 year later at the same location. The three isolates from cohort 2 , which belonged to serovar IB-2, had identical amino acid sequences and PFGE patterns, but differed in sequence and PFGE patterns from other IB-2 isolates and from other serovars tested.

In contrast to the sequence identity shown between the epidemiologically linked isolates, comparisons between unlinked isolates of the same serovar showed wide sequence diversity. With the exception of SU105, as discussed above, the only isolates to show sequence identity within a serovar were those from a cohort of partners. The degree of sequence diversity within serovars varied considerably. Among the IB-2 serovar, isolates differed from cohort 2 isolates at between one 


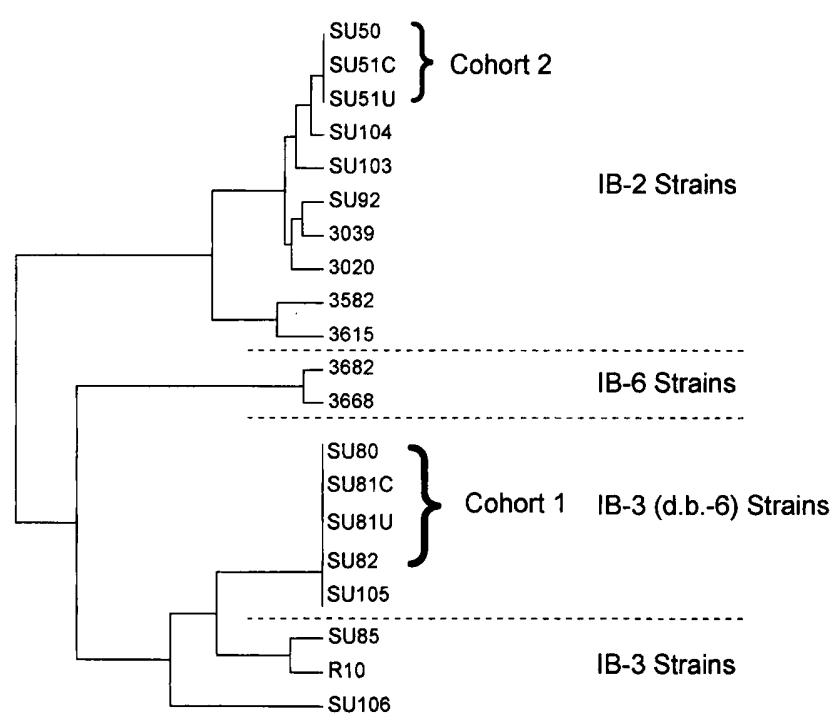

Fig. 2. Dendrogram showing the relationship between gonococcal PIB sequences. The sequences shown in Fig. 1 were compared with the UWGCG Pileup program using the BBSRC SEQNET facility. Horizontal dotted lines separate strains according to serovar, and braces enclose sequences from cohorts 1 and 2 .

(SU104) and thirteen (3582) positions. The sequence of the two IB- 6 isolates differed by two amino acids, while the IB- 3 isolates showed sequence differences in a total of nine positions.

\section{Epitope mapping studies}

The availability of sequence information facilitates detailed mapping of the epitopes recognized by mAbs. Previous studies with the SM-series mAbs have shown that most recognize linear epitopes in the Var1 region of strain P9 (IB-26) between amino acid residues 190 and 200. Despite their identical reactivity with these mAbs, the IB-2 isolates in the current study showed sequence differences in this region. The previously determined epitope specificities of mAbs SM22, SM21 and SM203 were found to be the closely related sequences ${ }^{190} \mathrm{IEYEHQVY}^{197}, \quad{ }^{192} \mathrm{YE}(\mathrm{H} / \mathrm{Y}) \mathrm{Q}(\mathrm{V} / \mathrm{A}) \mathrm{Y}^{197}$ and ${ }^{192}$ YEXQX $^{196}$ (Butt et al., 1990b). Inspection of the different sequences found in the IB-2 group of isolates showed that none contain potentially reactive sequences, while the IB-3 (d.b.-6) isolates all contain the sequence ${ }^{190}$ IEYEHQVY ${ }^{197}$, which includes an epitope for each of the three mAbs. Thus, the determined sequence, immunological reactivity and epitope specificity are in accord. Similarly, all isolates from both the IB-2 and IB-3 (d.b.6) groups reacted with mAbs SM24 and SM198 and all contain the sequences ${ }^{198}$ SIPS $^{201}$ and ${ }^{107}$ WESGK $^{111}$, which are the respective epitopes for these mAbs.

The epitope specificity of the mAbs used for serovar determination had not been previously reported. To investigate the effect of sequence variation on reaction with these mAbs, a series of overlapping decapeptides
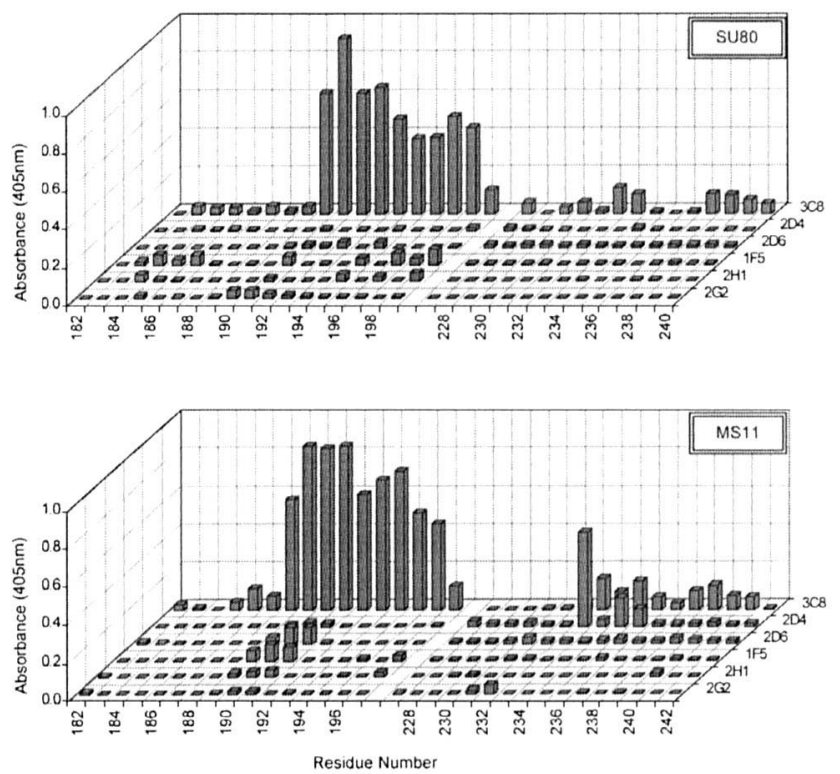

Fig. 3. Epitope mapping with mAbs used for serovar classification. Decapeptides corresponding to the Var1 and Var2 regions of gonococcal strains SU80, SU50, R10 and MS11 were synthesized with adjacent peptides differing by a single amino acid residue. Peptides were reacted in ELISA with the serotyping mAbs. The results shown were obtained with sequences corresponding to SU80 and MS11; strains SU50 and R10 gave essentially identical patterns to those obtained with SU80.

were synthesized on polyethylene pins, in which adjacent peptides differed by a single amino acid residue. The sequences used corresponded to the Var1 and Var2 regions of the IB-3 (d.b.-6) strains from cohort 1, the IB2 strains from cohort 2 and the previously determined sequences from strains R10 (IB-3) and MS11 (IB-9) which, together, provided epitopes recognized by all of the serotyping mAbs. Of the six antibodies, 1F5, 2D6, $2 \mathrm{G} 2$ and $2 \mathrm{H} 1$ showed little or no reaction with sequences from any of the four strains (Fig. 3). In contrast, mAb $3 \mathrm{C} 8$ reacted strongly with several peptides from all the Var1 regions. These peptides had in common the sequence ${ }^{198} \mathrm{SI}^{199}$, which has previously been defined as the minimum epitope recognized by mAb SM24. Antibody 2D4 did not react with any of the Var1 sequences, but did react with peptide ${ }^{231} \mathrm{KLYQNQLVRD}{ }^{240}$ from the Var2 of strain MS11. This sequence showed little similarity to the equivalent region of the other strains, in accord with their lack of reactivity with this $\mathrm{mAb}$.

\section{PFGE analysis}

PFGE was carried out to investigate possible relationships between strains. Analysis of the PFGE patterns also showed that unrelated isolates within a serovar all gave different profiles. The greatest similarity was seen between the cohort 1 isolates and strain SU105, which had an identical PIB sequence and differed by a single 
(a)

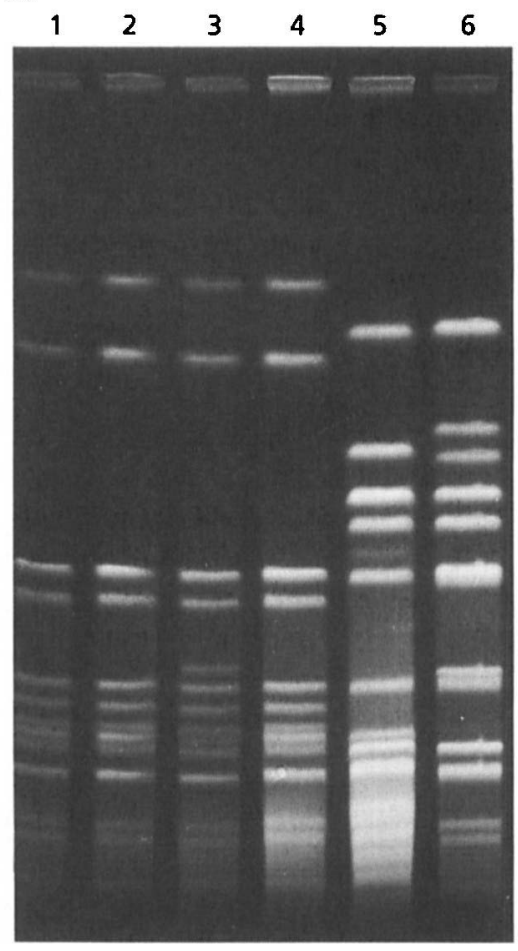

(b)

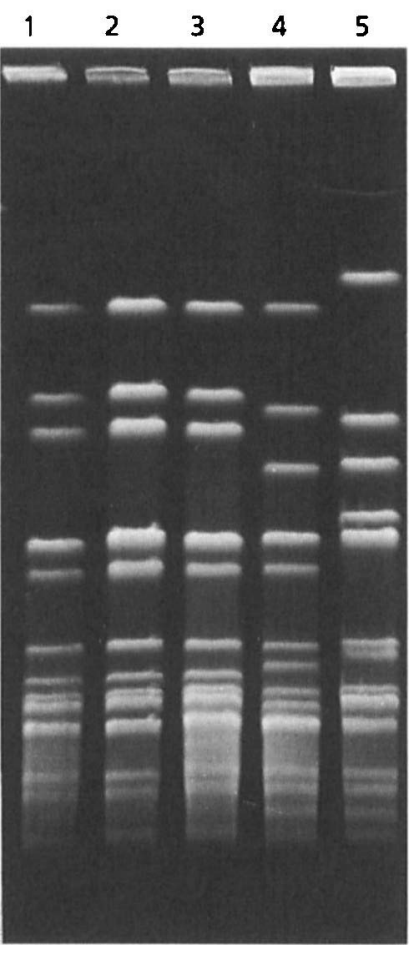

Fig. 4. PFGE patterns of isolates from cohorts 1 and 2. (a) Isolates from cohort 1 SU81C (lane 1), SU82C (2) and SU80 (4); strain SU105 (3) with identical PIB sequence and unrelated strains SU104 (5) and SU106 (6). (b) Isolates from cohort 2 SU51C (lane 1), SU51U (2) and SU50 (3); and unrelated strains SU85 (4) and SU103 (5).

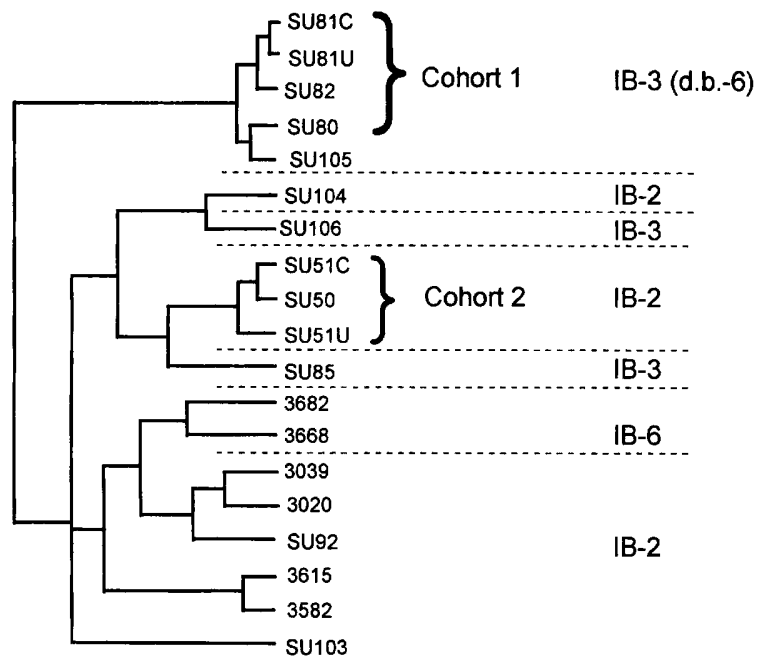

Fig. 5. Dendrogram showing the relationship between the PFGE patterns obtained with the gonococcal isolates shown in Fig. 1. Patterns were compared using GelManager software (BioSystematica). Horizontal dotted lines separate strains according to serovar, and braces enclose sequences from cohorts 1 and 2 .

band on PFGE (Fig. 4). However, other pairs of strains with very similar sequences gave widely different PFGE patterns. The sequence of strain SU104 differed from the cohort 2 group by a single amino acid, but quite distinct PFGE patterns were obtained, while SU85, the strain which showed the most similar PFGE pattern to cohort
2, differed by 26 residues. A dendrogram based on the relationships between the PFGE patterns was computed and showed no precise correlation between the PFGE pattern and PIB sequence obtained (Fig. 5).

\section{DISCUSSION}

The ability to differentiate reliably between unrelated gonococcal strains is essential for studies of the epidemiology of gonorrhoea. Serotyping with panels of $\mathrm{mAb}$ which differentiate strains on the basis of antigenic differences in PIA or PIB has facilitated such studies, but methods which permit further discrimination are required. The aim of this study was to investigate the potential extent of variations of PIB within a single serovar, which might permit further differentiation of strains. Although all the strains selected were identified as IB-2 on initial isolation, several were subsequently found to react in co-agglutination as IB-3. Previous studies have shown that determination of gonococcal serovar is potentially subject to problems of reproducibility which are influenced by preparation of the reagents used and interpretation of the results (Ison et al., 1992). As found in the present study, consistency in serovar determination over a period of years may therefore be a particular problem. The development of potentially more reliable molecular methods based on knowledge of the structure of the por gene, which encodes PI, are therefore a logical development of the current serotyping schemes.

Comparison of PIA and PIB with the analogous porins from meningococci has led to a model for the organi- 
zation of the Neisseria porins within the outer membrane. The model predicts a series of amphipathic transmembrane $\beta$-sheets which generate eight surfaceexposed loops. The membrane-bound regions are highly conserved between the different porin classes, while the predicted loops show extensive variation in both length and amino acid composition. Within each class so far examined, sequence diversity is far more restricted. The original studies with PIB compared the sequences of the protein from three strains of different serovar and revealed that sequence variation between the three strains was largely located in two regions designated Var1 and Var2 (Butt et al., 1990b), which were subsequently shown to be located at the apices of predicted loops 5 and 6 (van der Ley et al., 1991). In addition, epitope-mapping studies demonstrated that the SM series of $m A$ bs reacted with the Var1 sequences in loop 5 , suggesting that this region was the predominant influence on antigenic specificity. The current studies reveal that the situation is more complex than this: sequence variations are not confined to the Var1 and Var2 regions in loops 5 and 6, but occur elsewhere in the protein, particularly in loops 1,3 and 7.

Epitope-mapping studies with the mAbs used to prepare reagents for serotyping confirmed that the previously designated Var1 and Var2 regions do contribute to serovar specificity: antibody $3 \mathrm{C} 8$ reacted with the same highly conserved sequence in loop 5 previously shown to be responsible for broad specificity of $\mathrm{mAb}$ SM24, while $\mathrm{mAb} 2 \mathrm{D} 4$ reacted with a sequence from the loop 6 region of PIB of strain MS11, but which was not present in any of the strains from the present study. These locations are in accord with studies of Carbonetti et al. (1988), who used artificial hybrid PIA/PIB molecules to demonstrate that the epitiopes for 3C8 and 2D4 were located in a central region of PIB between residues 150 and 270, with $3 \mathrm{C} 8$ closest to the $\mathrm{N}$-terminus. In the current study, the remaining four $\mathrm{mAbs}$ failed to react with any sequences corresponding to the Var1 and Var2 regions of the strains tested. Although this lack of reactivity may result from the epitopes recognized being conformational in nature, other sequences outside these regions must also contribute to serovar specificity. This would be similar to the situation with PIA, where some serovar-specific antibodies react with linear epitopes in loop 6, while others recognize conformational epitopes apparently located in other loops (Mee et al., 1993). In the studies with PIA, it was possible, by comparing sequence differences with $\mathrm{mAb}$ reactivity, to identify regions that appeared to contribute to such determinants. In the present study it has not been possible to identify epitopes by sequence comparison, but the occurrence of sequence variations in other predicted loop regions suggests surface location and, hence, exposure to immunological pressure. Certainly, the fact that both loop 5 and loop 6 sequences of IB- 2 cohort 2 strains are identical to that of the previously published sequence of strain P9 (IB-26) indicates that other regions of the protein must also contribute to serovar specificity.

The widespread occurrence of sequence variations of
PIB within a serovar has potentially important implications. Differentiation between gonococcal strains is important not only for studies of the epidemiology of gonococcal infection, but also in providing information on patterns of sexual mixing used in mathematical models of HIV-transmission dynamics (Anderson $e t$ al., 1990). Conventional differentiation of gonococcal strains, based on a combination classification of auxotype and serovar (A/S), suffers from a lack of discriminatory power (O'Rourke et al., 1995). Other methods such as PFGE (Poh \& Lau, 1993) and Opatyping (O'Rourke et al., 1995) are capable of providing much greater resolving power, but since they rely on pattern recognition, they are relatively subjective, particularly when comparing results between laboratories. The occurrence of the 'silent' differences within a serovar shows that, potentially, PIB holds considerably more epidemiological information than can be obtained using current serological reagents. The use of DNAbased methods provides the potential for greater reproducibility and, although methods based on direct por sequencing are relatively complex, such studies should provide information for the design of improved reagents for gonococcal differentiation based on gene-probe techniques, as has been proposed for the related por $A$ gene, which encodes the class 1 porin responsible for meningococcal subtype specificity (Maiden et al., 1992).

The practical use of porin sequence information in epidemiological studies would clearly be dependent on stability in the por gene during transmission over a useful period of time. While it is likely that PI is subject to immunological pressure to undergo variation, the timescale of such variation is unknown. However, evidence for por gene stability is provided in the current study, by comparison of cohort 1 isolates with strain SU105. These strains, which were isolated from the same geographical location, but separated by a period of 1 year, were the only unlinked isolates to have an identical PI sequence. In addition, they also share the unusual AHU/IB-3 combination of auxotype and serovar, and differ in PFGE by a single band, indicating a close genetic relationship. This would be consistent with the stability of PIB during transmission within a community over this period. It would also be in accord with studies on the meningococcal por $A$ gene which suggest that the gene is stable during epidemic transmission over a period of decades (Suker et al., 1994).

In addition to its importance for serovar specificity, PIB is an important candidate antigen for vaccination against gonorrhoea (Heckels et al., 1990; Elkins et al., 1992). The further diversity of PIB revealed in the current studies strengthens the suggestion that such strategies should focus on antigenic determinants, such as that recognized by mAb SM24, which are known to be widely shared between strains (Heckels et al., 1990).

\section{ACKNOWLEDGEMENTS}

This work was supported by the Medical Research Council (J.E.H.) and the Wellcome Trust (C.A.I.). 


\section{REFERENCES}

Anderson, R. M., Gupta, S. \& Ng, W. (1990). The significance of sexual partner contact networks for the transmission dynamics of HIV. J Acquired Immune Defic Syndr 2, 417-419.

Brooks, J. L., Fallon, R. J. \& Heckels, J. E. (1995). Sequence variation in class 1 outer membrane protein in Neisseria meningitidis isolated from patients with meningococcal infection and close household contacts. FEMS Microbiol Lett 128, 145-150.

Butt, N. J., Lambden, P. R. \& Heckels, J. E. (1990a). The nucleotide sequence of por gene encoding expression of outer membrane protein PIB in Neisseria gonorrhoeae strain P9. Nucleic Acids Res $14,4258$.

Butt, N. J., Virji, M., Vayreda, F., Lambden, P. R. \& Heckels, J. E. (1990b). Gonococcal outer-membrane protein PIB: comparative sequence analysis and localization of epitopes which are recognized by type-specific and cross-reacting monoclonal antibodies. $J$ Gen Microbiol 136, 2165-2172.

Carbonetti, N. H. \& Sparling, P. F. (1987). Molecular cloning and characterization of the structural gene for protein $\mathrm{I}$, the major outer membrane protein of Neisseria gonorrhoeae. Proc Natl Acad Sci USA 84, 9084-9088.

Carbonetti, N. H., Simnad, V. I., Seifert, H. S., So, M. \& Sparling, P. F. (1988). Genetics of protein I of Neisseria gonorrhoeae: construction of hybrid porins. Proc Natl Acad Sci USA 85, $6841-6845$

Douglas, J. T., Lee, M. D. \& Nikaido, H. (1981). Protein I of Neisseria gonorrhoeae outer membrane is a porin. FEMS Microbiol Lett 12, 305-309.

Elkins, C., Carbonetti, N. H., Varela, V. A., Stirewalt, D., Klapper, D. G. \& Sparling, P. F. (1992). Antibodies to N-terminal peptides of gonococcal porin are bactericidal when gonococcal lipopolysaccharide is not sialylated. Mol Microbiol 6, 2617-2628.

Gill, M. J. (1991). Serotyping Neisseria gonorrhoeae: a report of the fourth international workshop. Genitourin Med 67, 53-57.

Gotschlich, E. C., Seiff, M. E., Blake, M. S. \& Koomey, M. (1987). Porin protein of Neisseria gonorrboeae: cloning and gene structure. Proc Natl Acad Sci USA 84, 8135-8139.

Heckels, J. E., Virji, M. \& Tinsley, C. R. (1990). Vaccination against gonorrhoeae: the potential protective effect of immunization with a synthetic peptide containing a conserved epitope of gonococcal outer membrane protein IB. Vaccine 8, 225-230.

Ison, C. A., Whitaker, L. \& Renton, A. (1992). Concordance of auxotype/serovar classes of Neisseria gonorrhoeae between sexual contacts. Epidemiol Infect 109, 265-271.

Knapp, J. S., Tam, M. R., Nowinski, R. C., Holmes, K. K. \& Sandstrom, E. G. (1984). Serological classification of Neisseria gonorrhoeae with use of monoclonal antibodies to gonococcal outer membrane protein I. J Infect Dis 50, 44-48.
Knapp, J. S., Holmes, K. K., Bonin, P. \& Hook, E. W. (1987). Epidemiology of gonorrhoea: distribution and temporal changes in auxotype/serovar classes of Neisseria gonorrboeae. Sex Transm Dis 14, 26-32.

McGuinness, B. T., Lambden, P. R. \& Heckels, J. E. (1993). Class 1 outer membrane protein of Neisseria meningitidis: epitope analysis of the antigenic diversity between strains, implications for subtype definition and molecular epidemiology. Mol Microbiol 7, 505-514.

Maiden, M. C. J., Bygraves, J. A., McCarvil, J. \& Feavers, I. M. (1992). Identification of meningococcal serosubtypes by polymerase chain reaction. J Clin Microbiol 30, 2835-2841.

Mee, B. J., Thomas, H., Cooke, S. J., Lambden, P. R. \& Heckels, J. E. (1993). Structural comparison and epitope analysis of outermembrane protein PIA from strains of Neisseria gonorrboeae with differing serovar specificities. J Gen Microbiol 139, 2613-2620.

O'Rourke, M., Ison, C. A., Renton, A. M. \& Spratt, B. G. (1995). Opa-typing: a high resolution tool for studying the epidemiology of gonorrhoea. Mol Microbiol 17, 865-875.

Poh, C. L. \& Lau, Q. C. (1993). Subtyping of Neisseria gonorrboeae auxotype-serovar groups by pulsed-field gel-electrophoresis. $J$ Med Microbiol 38, 366-370.

Sandstrom, E. G., Chen, K. C. S. \& Buchanan, T. M. (1982). Serology of Neisseria gonorrhoeae: co-agglutination serogroups WI and WII/III correspond to different outer membrane protein molecules. Infect Immun 38, 462-470.

Suker, J., Feavers, I. M., Achtman, M., Morelli, G., Wang, J. F. \& Maiden, M. C. J. (1994). The porA gene in serogroup A meningococci: evolutionary stability and mechanism of genetic variation. Mol Microbiol 12, 253-265.

Van der Ley, P., Heckels, J. E., Virji, M., Hoogerhout, P. \& Poolman, J. T. (1991). Topology of outer membrane porins in pathogenic Neisseria spp. Infect Immun 59, 2963-2971.

Virji, M., Zak, K. \& Heckels, J. E. (1986). Monoclonal antibodies to gonococcal outer membrane protein IB: use in investigation of the potential protective effect of antibodies directed against conserved and type-specific epitopes. J Gen Microbiol 132, $1621-1629$.

Virji, M., Fletcher, J. N., Zak, K. \& Heckels, J. E. (1987). The potential protective effect of monoclonal antibodies to gonococcal outer membrane protein IA. J Gen Microbiol 133, 2639-2646.

Zak, K., Diaz, J. L., Jackson, D. \& Heckels, J. E. (1984). Antigenic variation during infection with Neisseria gonorrboeae: detection of antibodies to surface proteins in sera of patients with gonorrhea. J Infect Dis 149, 166-173.

Received 12 July 1996; revised 30 October 1996; accepted 14 November 1996. 